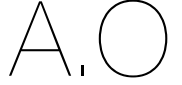

ARTIGO ORIGINAL

1 Faculdade de Ciências da Nutrição e Alimentação da Universidade do Porto, Rua do Campo Alegre,

n. ${ }^{\circ} 823$,

4150-180 Porto,

Portugal

2 Universidade de Trás-os-Montes e Alto

Douro,

Quinta de Prados,

5000-801 Vila Real,

Portugal

${ }^{3} \mathrm{CBQF}$ - Centro de Biotecnologia e Química Fina - Laboratório Associado, Escola

Superior de Biotecnologia da Universidade Católica Portuguesa,

Rua Diogo Botelho, n. ${ }^{1327,}$ 4169-005 Porto, Portugal

${ }^{4}$ GreenUPorto Sustainable Agrifood

Production Research Centre,

Edifício de Ciências Agrárias,

Rua da Agrária, n. ${ }^{\circ} 747$, 4485-646 Vairão, Portugal

${ }^{5}$ CITAB - Centre for the Research and Technology of Agro-Environmental and Biological Sciences,

Quinta de Prados

Edifício Reitoria,

5000-801 Vila Real,

Portugal

Endereço para correspondência:

Margarida Liz Martins Quita de Prados, 5000-801 Vila Real, Portugal mliz@utad.pt

Histórico do artigo:

Recebido a 6 de agosto de 2020 Aceite a 30 de setembro de 2020

\section{AVALIAÇÃO DAS PERDAS DE ALIMENTOS NA PRODUÇÃO DE REFEIÇÕES EM UNIDADES DE ALIMENTAÇÃO ESCOLAR}

\author{
EVALUATION OF MEALS PRODUCTION FOOD LOSSES IN \\ SCHOOL FOOD UNITS
}

Flávia Mota Ribeiro'; Margarida Liz Martins ${ }^{2-4,5}$

\section{RESUMO}

INTRODUÇÃo: O desperdício alimentar assume-se como uma problemática presente no setor da alimentação coletiva, sendo de enorme importância a sua redução. Para tal é necessário quantificá-lo, quer durante a produção de refeições, quer após o seu consumo, com o objetivo de identificar as etapas geradoras de maior desperdício, visando a sua redução.

OBJETIVOS: Avaliar as perdas de alimentos nas diferentes etapas da produção do almoço escolar fornecido em cantinas de escolas básicas de ensino público e de educação pré-escolar de um Município Português.

METODOLOGIA: A recolha de dados decorreu em 18 unidades de alimentação, através do acompanhamento de todas as etapas de produção de refeições. Foram avaliadas as perdas resultantes dos processos de descasque, corte e desossagem e, as sobras, que corresponderam a todos os alimentos confecionados e não servidos. Os constituintes do prato foram classificados como componente proteica, acompanhamento fornecedor de hidratos de carbono e acompanhamento de produtos hortícolas. Todos os procedimentos de quantificação foram realizados com recurso ao método de pesagem agregada.

RESULTADOS: Foram avaliadas as perdas de produção de 10 refeições diferentes, destinadas ao fornecimento de 1.451 almoços e as sobras de 18 refeições diferentes, correspondentes a um total de 1.998 almoços.

Observou-se uma percentagem média de perdas de 14,2\%, sendo 20,7\% referentes ao processo de descasque e 6,2\% referentes ao processo de corte e desossagem. A percentagem média de sobras foi de 14,6\%, sendo que a sopa apresentou um valor médio de sobras de $14,4 \%$ e o prato de $14,9 \%$.

CONCLUSÕES: O elevado valor de perdas observado demonstra a necessidade de melhoria no que respeita às técnicas de preparação aplicadas. Os valores de sobras encontram-se acima dos limites recomendados pela literatura (3\%), evidenciando a necessidade de intervenção para redução do desperdício alimentar.

\section{PALAVRAS-CHAVE}

Almoço escolar, Desperdício alimentar, Perdas, Sobras, Unidade de Alimentação

ABSTRACT

INTRODUCTION: Food waste is a problem present in our daily, and its reduction is essential. Thus, it is necessary to quantify it both during the meals production and after consumption, aiming to identify the phases with high food waste values, targeting its reduction. OBJECTIVES: To evaluate food losses in the school lunch production provided in primary school canteens from a Portuguese Municipality.

METHODOLOGY: Data collection was carried out in 18 food units, through monitoring all stages of meals production. Losses resulted from the debarking, cutting and boning processes and the leftovers corresponded to all food prepared and not served were evaluated. The constituents of the main dish were classified as protein component, carbohydrate source and vegetable source. All quantification procedures were performed using the aggregate weighing method.

RESULTS: The production losses of 10 different meals, corresponding to 1451 lunches and the leftovers of 18 different meals, corresponding to a total of 1998 lunches were evaluated. A mean value for losses of $14.2 \%$ was observed, being $20.7 \%$ of the debarking process and $6.2 \%$ of the cutting and deboning process. Leftovers corresponded to $14.6 \%$, resulting a mean value of $14.4 \%$ from soup and $14.9 \%$ of leftovers from main dish.

CONCLUSIONS: The high value of losses found demonstrates the improvement need concerning to meals preparation techniques. Leftovers values are above the limits recommended by the literature (3\%), pointing the need for intervention, in order to reduce food waste.

KEYWORDS

School lunch, Food waste, Losses, Leftovers, Food unit 


\section{INTRODUÇÃO}

O desperdício alimentar é uma realidade negativamente presente no nosso quotidiano, representando um problema global e transversal para o qual é necessário encontrar estratégias com vista à sua minimização $(1,2)$. Neste sentido, o desperdício alimentar tem merecido uma atenção crescente nos últimos anos (3-5). Em Portugal, a Assembleia da República, nos termos do n. 5 do artigo $166 .^{\circ}$ da Constituição, declarou o ano de 2016 como o "Ano Nacional do Combate ao Desperdício Alimentar" com a emissão de um conjunto de recomendações ao Governo para prevenir o desperdício.

Do ponto de vista moral a questão do desperdício alimentar é ainda interpelada pelo facto de milhões de toneladas de alimentos serem lançados ao lixo anualmente, contrastando com uma realidade mundial em que um sexto da população passa fome $(3,6)$, acrescido ao facto de que se sabe que a atual produção de alimentos seria suficiente para alimentar toda a população mundial (6). Face a este problema, a redução do desperdício alimentar surge enquadrada nos Objetivos de Desenvolvimento Sustentável da Organização das Nações Unidas e na Agenda 2030, sendo identificado como um dos objetivos "reduzir para metade o desperdício de alimentos per capita a nível mundial até 2030" (7).

A perda de alimentos é definida como "a diminuição da quantidade ou da qualidade dos alimentos", englobando os produtos destinados ao consumo humano que não são consumidos ou que tiveram uma redução na qualidade que se refletiu no seu valor nutricional, valor económico ou na sua segurança alimentar (5). Sabe-se que esta perda de alimentos ocorre em toda a cadeia de abastecimento, desde a produção agrícola até ao consumo final $(6,8)$.

Globalmente 1/3 dos alimentos produzidos para consumo humano é perdido ou desperdiçado $(8,9)$. Em Portugal está descrito que esta perda é de aproximadamente 17\%, correspondendo a cerca de 1 milhão de toneladas de alimentos por ano (3). Este nível de resíduos tem impactos económicos, sociais e ambientais que são cada vez mais difíceis de ignorar (10). Por ano, o valor de alimentos desperdiçados globalmente é estimado em 1 trilião de dólares (5), sendo que a perda de alimentos e o desperdício têm também impactos ambientais negativos devido à água, solo, energia e outros recursos naturais usados para produzir alimentos que ninguém consome (5). No que diz respeito às Unidades de Alimentação e Nutrição (UAN), reduzir o desperdício alimentar pode aumentar a eficiência das mesmas (11), conduzir a diversos benefícios, particularmente a nível nutricional, com a otimização dos nutrientes disponíveis para a alimentação dos diferentes grupos populacionais que realizam as suas refeições em estabelecimentos de restauração coletiva, passível de obter através de estratégias como o aproveitamento integral dos alimentos e consequentemente dos nutrientes presentes nas cascas e outras partes geralmente rejeitadas. Para as unidades acrescem ainda os ganhos económicos, possibilitando aumentar a qualidade e satisfação do consumidor com o serviço disponibilizado e a proteção ambiental (12). O controlo das etapas de produção e distribuição das refeições, assim como a quantificação dos desperdícios podem ser um indicador de qualidade do serviço prestado pela UAN (13).

Nas UAN em análise no presente estudo observam-se já algumas práticas com o objetivo de redução do desperdício durante a preparação de refeições, nomeadamente a utilização de produtos de 4. ${ }^{\mathrm{a}}$ gama. No entanto, torna-se necessário quantificar efetivamente a perda de alimentos durante todo o processo de produção de refeições e identificar as etapas que podem gerar maiores perdas, para posteriormente poder identificar possíveis causas, bem como, definir as estratégias adequadas à redução do desperdício neste setor. Assim, e considerando que a maioria dos estudos reflete o desperdício sobre a forma de restos, após o consumo, e dada a escassez de estudos publicados que quantifiquem o desperdício alimentar especificamente na preparação de refeições, torna-se crucial avaliar este desperdício para contribuir para a sua minimização, sendo este o objetivo principal do presente trabalho (14).

\section{OBJETIVOS}

Avaliar as perdas de alimentos no processo de produção do almoço escolar fornecido em cantinas de escolas básicas de ensino público e de educação pré-escolar.

\section{METODOLOGIA}

\section{Seleção da Amostra}

O presente trabalho de investigação realizou-se em unidades de alimentação de escolas básicas de ensino público e educação préescolar da rede pública de um Município Português. A amostra usada no presente trabalho foi selecionada de forma não probabilística e por conveniência, sendo constituída por 18 unidades de alimentação, 10 das quais apresentavam preparação, confeção e distribuição de refeições e 8 unidades que englobavam apenas a fase de distribuição de refeições.

\section{Recolha de Dados}

A recolha de dados decorreu durante a preparação e distribuição do almoço, sendo cada uma das unidades visitada uma vez.

A refeição tipo servida englobava sopa, prato constituído por componente proteica (CP), acompanhamento fornecedor de hidratos de carbono (AFHC) e acompanhamento de produtos hortícolas (APH), sobremesa (fruta ou doce), pão de mistura e água de abastecimento da rede pública. Relativamente à classificação do prato, quando este apresentava as três componentes separadamente foi classificado como não composto. Quando se verificou a ocorrência da agregação de dois, ou mais, componentes do prato, classificou-se o mesmo como prato composto.

No presente estudo, considerou-se como desperdício alimentar as perdas de alimentos na produção de refeições, designadas ao longo do trabalho, por perdas alimentares ou perdas e as sobras resultantes do almoço escolar. Foram consideradas como perdas alimentares todas as partes descartadas durante a preparação dos alimentos, nomeadamente nos processos de descasque, corte e desossagem. Consideraram-se perdas de descasque as perdas resultantes de todos os processos que envolviam a retirada de cascas e, como perdas de corte e desossagem as perdas resultantes dos processos onde se verificava a necessidade de cortar em porções, retirar peles, gorduras e ossos das peças de carnes. No que respeita às sobras foram considerados todos os alimentos confecionados que não foram distribuídos (15).

Para os produtos utilizados de $4 .^{a}$ gama não existiam perdas associadas ao processo de preparação, bem como, no caso dos produtos secos (por exemplo: massa, arroz). Sempre que se recorreu à utilização de automatismo para o descasque de batatas e outros tubérculos (através de máquina de descascar batatas) não foi possível a quantificação das perdas inerentes a este processo.

Os procedimentos de quantificação foram realizados com recurso ao método de pesagem, sendo utilizada uma balança digital Becken ${ }^{\circledR}$ modelo BKS-2389, com capacidade máxima de $10 \mathrm{~kg}$ e precisão $1 \mathrm{~g}$. Todas as pesagens e procedimentos metodológicos foram efetuados pelo mesmo avaliador. 


\section{Avaliação das perdas:}

Para a avaliação das perdas decorrentes dos processos de produção das refeições, todos os alimentos, passíveis de ocorrerem perdas, foram pesados em bruto, sendo posteriormente pesadas as perdas decorrentes de cada um dos processos de descasque ou corte e desossagem. O valor das perdas foi obtido através da diferença entre o peso do recipiente com os alimentos descartados e o peso do recipiente vazio. Posteriormente foi calculada a percentagem de perdas através da seguinte fórmula, tendo por base a fórmula referenciada por outros autores para o cálculo das sobras (15):

$$
\text { Perdas }(\%)=\frac{\text { Peso do desperdício do alimento }(g)}{\text { Peso bruto do alimento }(g)} \times 100
$$

O valor de Perdas Totais (PT), por escola, e por etapa, foi calculado através da seguinte fórmula:

$$
P T(\%)=\frac{\text { Peso do desperdício de todos os alimentos }(g)}{\text { Peso bruto dos alimentos utilizados }(g)} \times 100
$$

\section{Avaliação do desperdício sob a forma de sobras:}

Após a confeção do almoço pesaram-se os seus constituintes, categorizados como sopa, $\mathrm{CP}, \mathrm{AFHC}$ e APH, sendo sempre subtraído o valor correspondente ao recipiente de pesagem utilizado. Nos pratos compostos, as pesagens foram realizadas agregando os diferentes alimentos fornecidos. Nos pratos não compostos, as pesagens foram efetuadas pesando-se separadamente os diferentes constituintes do prato. No final da refeição todos os alimentos que não foram distribuídos foram novamente pesados. O valor das sobras foi obtido pela diferença entre o valor inicial encontrado e a quantidade de alimentos não distribuídos no final da refeição. A percentagem de sobras foi obtida através da seguinte fórmula (15):

$$
\operatorname{Sobras}(\%)=\frac{\text { Peso das sobras }(g)}{\text { Peso total da refeição confecionada }(g)} \times 100
$$

Não foram consideradas as perdas do processo de produção nem as sobras da sobremesa, uma vez que no período em avaliação só foi fornecida fruta inteira (com casca) como sobremesa. Esta era distribuída no final da refeição dando a possibilidade aos alunos de consumir no recreio ou no período da tarde, o que inviabilizou a quantificação de possíveis sobras.

De modo a testar a metodologia a utilizar, realizou-se um teste piloto numa unidade de confeção de um estabelecimento escolar responsável pela produção diária de 100 refeições. Após a realização do teste-piloto realizaram-se os ajustes necessários à metodologia previamente definida, nomeadamente nos tempos definidos para a pesagem para minimizar perturbações no serviço de alimentação. Os dados recolhidos durante o teste-piloto foram excluídos da amostra final.

\section{Análise dos Dados}

A análise de dados foi efetuada com recurso ao programa Microsoft Excel ${ }^{\circledR} 2017$, através da aplicação das fórmulas para cálculo de perdas, sobras e cálculo de médias.

\section{RESULTADOS}

\section{Caracterização da Amostra}

Foram avaliadas as perdas de produção de 10 refeições diferentes, destinadas ao fornecimento de 1.451 almoços e as sobras de 18 refeições diferentes, correspondentes a um total de 1.998 almoços, correspondendo $77,8 \%$ a pratos classificados como compostos.

\section{Avaliação das Perdas na Produção dos Almoços}

Foi contabilizado um total de $84,2 \mathrm{~kg}$ de alimentos utilizados (Tubérculos, Hortícolas, Carne e Pescado), passíveis de sofrerem perdas, para a produção dos almoços, sendo desperdiçados $11,9 \mathrm{~kg}$ de alimentos nas etapas de preparação, correspondendo a um total de perdas de $14,2 \%$. A percentagem média de perdas na produção do almoço por unidade de alimentação variou entre 4,8\% e 29,8\%, sendo o alimento com maior percentagem de perda a abóbora, registando-se a perda de 44,4\% da abóbora utilizada. Em contrapartida, o alimento onde se verificou uma menor perda foi a cebola, com uma percentagem de 2,6\% de perdas no processo de preparação. Entre as duas etapas avaliadas (descasque e corte/desossagem), a que registou a percentagem de perdas mais elevada foi a etapa de descasque com uma média de perdas de 20,7\% (Tabela 1).

\section{Avaliação do Desperdício sob a Forma de Sobras}

No total foram produzidos $804,1 \mathrm{~kg}$ de alimentos, dos quais $686,4 \mathrm{~kg}$ foram distribuídos, resultando assim numa percentagem de 14,6\% de sobras. No que respeita à sopa, foi confecionado um total de 426,7 kg, sendo distribuído 365,4 kg, o que perfaz um valor total de sobras de $61,3 \mathrm{~kg}$, equivalente a $14,4 \%$ do que foi confecionado. Relativamente ao prato, foram produzidos $377,5 \mathrm{~kg}$ de alimentos, sendo $321,0 \mathrm{~kg}$ distribuídos aos alunos, obtendo-se assim um valor total de sobras de $56,4 \mathrm{~kg}$, equivalente a $14,9 \%$.

O valor máximo de sobras no que respeita à sopa foi de $52,6 \%$, para a ementa de creme de cenoura e brócolos, por sua vez, o valor mínimo foi de $0,5 \%$ para o creme de brócolos. Relativamente ao prato o valor mais elevado foi de $54,1 \%$ do prato confecionado, carne de porco no tacho com tomilho, arroz branco e rodelas de cenoura cozidas, sendo que o valor mais baixo foi de $1,6 \%$, verificado na ementa de cotovelinhos estufados com cubos de peito de frango e rodelas de cenoura. Contabilizando a sopa e o prato, em conjunto, o valor total de sobras variou entre os 3,7\% e os 48,1\% (Tabela 2, Gráfico 1).

\section{DISCUSSÃO DOS RESULTADOS}

A quantificação das perdas alimentares é de extrema importância na gestão de uma UAN para a implementação de medidas de racionalização, redução de desperdícios e otimização da produtividade (15).

O presente estudo revelou uma percentagem de perdas na preparação das refeições de 14,2\%, e os valores médios de sobras quer para a sopa $(14,4 \%)$, quer para o prato $(14,9 \%)$ revelaram-se preocupantes e acima do valor de referência (3\%) identificado na literatura. Verificou-se que, das 18 unidades envolvidas na avaliação das sobras, apenas 4 apresentaram um valor médio de sobras para a sopa abaixo do limite aceitável, e 2 com valores médios de sobras para o prato abaixo de 3\% (1).

A enorme discrepância que se verifica entre as percentagens médias de perdas nas diferentes unidades (mínimo de 4,8\% e máximo de $29,9 \%$ ) pode dever-se às diferenças das técnicas e procedimentos utilizados entre manipuladores de alimentos. A utilização de técnicas de preparação distintas pode relacionar-se com a diferente formação que cada manipulador obteve, assim como a ausência dessa mesma formação, resultando assim na execução da mesma tarefa de forma distinta (16). Pode também ser consequência da inexistência de fichas 
Tabela 1

Percentagem de perdas por etapas de preparação das refeições

\begin{tabular}{|c|c|c|c|c|}
\hline UNIDADE & ALIMENTO & PERDAS NO DESCASQUE & $\begin{array}{l}\text { PERDAS NO CORTE } \\
\text { E DESOSSAGEM }\end{array}$ & $\begin{array}{l}\text { PERDAS TOTAIS (PT) POR } \\
\text { UNIDADE }\end{array}$ \\
\hline \multirow{2}{*}{ A } & Cenoura & $21,0 \%$ & & \multirow{2}{*}{$19,5 \%$} \\
\hline & Couve-coração & $16,6 \%$ & & \\
\hline \multirow{2}{*}{$\mathrm{B}$} & Cebola & $12,7 \%$ & & \multirow{2}{*}{$16,8 \%$} \\
\hline & Cenoura & $17,9 \%$ & & \\
\hline \multirow{4}{*}{ C } & Cenoura & $21,1 \%$ & & \multirow{4}{*}{$26,4 \%$} \\
\hline & Couve-coração & $20,0 \%$ & & \\
\hline & Cebola & $24,0 \%$ & & \\
\hline & Alface & $42,4 \%$ & & \\
\hline \multirow{4}{*}{$\mathrm{D}$} & Couve-branca & $15,6 \%$ & & \multirow{4}{*}{$18,7 \%$} \\
\hline & Cebola & $2,6 \%$ & & \\
\hline & Alho & $22,6 \%$ & & \\
\hline & Frango & & $20,7 \%$ & \\
\hline \multirow{4}{*}{$E$} & Cenoura & $42,3 \%$ & & \multirow{4}{*}{$29,8 \%$} \\
\hline & Couve-coração & $17,4 \%$ & & \\
\hline & Cebola & $20,2 \%$ & & \\
\hline & Alho & $23,5 \%$ & & \\
\hline \multirow{3}{*}{ G } & Cebola & $20,3 \%$ & & \multirow{3}{*}{$28,9 \%$} \\
\hline & Alho & $19,3 \%$ & & \\
\hline & Alface & $37,68 \%$ & & \\
\hline \multirow{4}{*}{ M } & Cenoura & $15,9 \%$ & & \multirow{4}{*}{$19,9 \%$} \\
\hline & Abóbora & $44,4 \%$ & & \\
\hline & Couve-coração & $10,0 \%$ & & \\
\hline & Tomate & $12,3 \%$ & & \\
\hline \multirow{2}{*}{$\mathrm{P}$} & Couve-coração & $19,0 \%$ & & \multirow{2}{*}{$22,6 \%$} \\
\hline & Cenoura & $28,4 \%$ & & \\
\hline \multirow{3}{*}{$Q$} & Lombarda & $8,9 \%$ & & \multirow{3}{*}{$4,8 \%$} \\
\hline & Abóbora & $27,0 \%$ & & \\
\hline & Fêveras & & $2,9 \%$ & \\
\hline \multirow{4}{*}{$\mathrm{s}$} & Couve-coração & $3,3 \%$ & & \multirow{3}{*}{$6,7 \%$} \\
\hline & Cebola & $14,4 \%$ & & \\
\hline & Cenoura & $9,9 \%$ & & \\
\hline & PT por etapa & $20,7 \%$ & $6,2 \%$ & \\
\hline
\end{tabular}

técnicas, não existindo assim uma padronização para o processo de preparação das refeições, resultando numa maior variabilidade durante a produção das mesmas (16). A elaboração das referidas fichas técnicas e a sua posterior aplicação, acompanhadas do devido treino dos manipuladores de alimentos, poderá assim mostrar-se fundamental para colmatar esta situação (17).

A etapa de corte e desossagem apresentou um valor de perdas baixo $(6,2 \%)$, o que pode ser justificado pelo facto de a maioria dos alimentos que constituem a CP já se encontrarem previamente preparados quando são rececionados nas diversas unidades de confeção. Caso não se verificasse este fator, e se fosse da responsabilidade das cozinheiras realizar esta preparação da $\mathrm{CP}$, este valor seria possivelmente superior ao encontrado uma vez que em contexto escolar é recomendado retirar, para além dos ossos, todas as gorduras e peles visíveis (18). No que diz respeito ao descasque, o valor médio encontrado (20,7\%) encontra-se abaixo do valor descrito num trabalho idêntico realizado numa Instituição Particular de Solidariedade Socia de S. João da Madeira, que descreveu uma média de perdas na etapa de descasque de $34,9 \%$ (19).

Comparado o valor médio de perdas obtido no presente trabalho $(14,2 \%)$, com outros trabalhos descritos na literatura com metodologia semelhante, percebe-se que existem valores médios de perdas superiores (34,1\%) (19), assim como inferiores (3,6\%) (20), este último estudo realizado em contexto escolar na Finlândia. De referir que se verificou a existência de poucos alimentos sujeitos a perdas, uma vez que se encontra generalizada a utilização de produtos de $4 .{ }^{\text {a gama com }}$ vista a essa mesma redução de perdas e de desperdícios nas UAN. No que diz respeito ao estabelecimento de um nível aceitável para as sobras, existe ainda uma indefinição, no entanto, diversos estudos referenciam o valor de $3 \%$ como limite de sobras aceitável para o setor da restauração $(15,17,21-23)$, valor este que foi descrito por Vaz, 2006 (1).

Os resultados observados podem ainda resultar de falhas no cumprimento das capitações, durante a produção e distribuição, devido ao incorreto planeamento das quantidades a produzir, falta de treino do colaborador para o correto empratamento ou a utilização de utensílios impróprios na linha de distribuição $(15,22)$. De referir ainda o incorreto planeamento das quantidades a confecionar e as faltas de alunos que previamente marcaram a refeição e por diversos motivos não compareceram na mesma. Realizar junto dos manipuladores uma consciencialização para a problemática (22), assim como ações de monitorização das quantidades distribuídas podem ser medidas úteis para o combate ao elevado valor de sobras encontrado em algumas das unidades de alimentação avaliadas.

Os resultados obtidos no âmbito do desperdício alimentar nas escolas são dificilmente comparáveis, devido às diferenças na tipologia de almoço escolar disponibilizado em diferentes países, assim como às recomendações especificas em vigor em cada país (24). Ainda assim, 
Tabela 2

Percentagem de sobras (\%) por unidade e por componente de refeição

\begin{tabular}{|c|c|c|c|}
\hline UNIDADE & COMPONENTE DA REFEIÇÃO & PERCENTAGEM DE SOBRA & TOTAL \\
\hline \multirow{2}{*}{ A } & Creme de brócolos & $0,5 \%$ & \multirow{2}{*}{$3,7 \%$} \\
\hline & Arroz de carnes à Provinciana e cenoura raspada & $8,0 \%$ & \\
\hline \multirow{2}{*}{ B } & Creme de espinafres & $13,2 \%$ & \multirow{2}{*}{$8,3 \%$} \\
\hline & Cotovelinhos estufados com cubos de peito de frango e rodelas de cenoura & $1,6 \%$ & \\
\hline \multirow{2}{*}{ C } & Juliana de legumes (repolho e cenoura) & $5,5 \%$ & \multirow{2}{*}{$7,3 \%$} \\
\hline & Esparguete de atum com salada de alface e milho & $12,1 \%$ & \\
\hline \multirow{2}{*}{$\mathrm{D}$} & Sopa de couve-branca e alho francês & $34,2 \%$ & \multirow{2}{*}{$25,8 \%$} \\
\hline & Frango assado com limão, arroz de cenoura e feijão verde cozido & $13,0 \%$ & \\
\hline \multirow{2}{*}{$\mathrm{E}$} & Sopa de couve-coração e abóbora & $7,6 \%$ & \multirow{2}{*}{$10,9 \%$} \\
\hline & Esparguete à bolonhesa com salada de tomate & $14,4 \%$ & \\
\hline \multirow{2}{*}{$\mathrm{F}$} & Creme de legumes com macedónia & $39,1 \%$ & \multirow{2}{*}{$48,1 \%$} \\
\hline & Carne de porco no tacho com tomilho, arroz branco e rodelas de cenoura cozida & $54,1 \%$ & \\
\hline \multirow{2}{*}{ G } & Creme de cenoura e brócolos & $52,6 \%$ & \multirow{2}{*}{$37,0 \%$} \\
\hline & Bacalhau à Brás com juliana de alface & $13,1 \%$ & \\
\hline \multirow{2}{*}{$\mathrm{H}$} & Creme de cenoura e brócolos & $31,2 \%$ & \multirow{2}{*}{$36,5 \%$} \\
\hline & Bacalhau à Brás com juliana de alface & $42,7 \%$ & \\
\hline \multirow{2}{*}{ I } & Creme de cenoura e brócolos & $9,5 \%$ & \multirow{2}{*}{$13,9 \%$} \\
\hline & Bacalhau à Brás com juliana de alface & $20,6 \%$ & \\
\hline \multirow{2}{*}{$\mathrm{J}$} & Creme de cenoura e brócolos & $10,5 \%$ & \multirow{2}{*}{$12,7 \%$} \\
\hline & Bacalhau à Brás com juliana de alface & $15,5 \%$ & \\
\hline \multirow{2}{*}{$\mathrm{L}$} & Sopa de grão com espinafres & $3,0 \%$ & \multirow{2}{*}{$21,5 \%$} \\
\hline & Bifinhos de frango grelhados com esparguete salteado e brócolos cozidos & $36,3 \%$ & \\
\hline \multirow{2}{*}{ M } & Creme de abóbora com spinafres & $14,7 \%$ & \multirow{2}{*}{$13,3 \%$} \\
\hline & Espirais com atum, ovo cozido, cubinhos de cenoura, milho e salada de alface & $12,0 \%$ & \\
\hline \multirow{2}{*}{$\mathrm{N}$} & Puré de couve-flor e cenoura & $1,4 \%$ & \multirow{2}{*}{$11,7 \%$} \\
\hline & Arroz de atum com juliana de repolho e cenoura salteada & $18,5 \%$ & \\
\hline \multirow{2}{*}{ O } & Puré de cenoura com saboia & $2,3 \%$ & \multirow{2}{*}{$7,7 \%$} \\
\hline & Filetes de pescada dourados no forno com salada de feijão frade, arroz e cenoura raspada & $13,3 \%$ & \\
\hline$D_{1}$ & Sopa de grão com espinafres & $26,0 \%$ & 2140 \\
\hline$P$ & Salada de grão com bacalhau, ovo cozido, batata aos cubos e couve-coração cozida & $15,1 \%$ & $21,4 \%$ \\
\hline & Sopa de couve lombarda e feijão & $10,8 \%$ & \\
\hline Q & $\begin{array}{l}\text { Fêveras de porco no tacho com molho de tomate e orégãos, puré de batata e brócolos } \\
\text { cozidos }\end{array}$ & $2,3 \%$ & $6,8 \%$ \\
\hline 8 & Puré de couve-flor e cenoura & $9,4 \%$ & $150 \%$ \\
\hline $\mathrm{R}$ & Perna de frango assada no forno com espirais salteadas e cenoura raspada & $21,0 \%$ & $15,9 \%$ \\
\hline $\mathrm{s}$ & Puré de couve-flor e cenoura & $39,4 \%$ & $252 \%$ \\
\hline $\mathrm{s}$ & Perna de frango assada no forno com espirais salteadas e cenoura raspada & $16,1 \%$ & $25,2 \%$ \\
\hline Módia & Sopa & $14,4 \%$ & $146 \%$ \\
\hline Media & Prato & $14,9 \%$ & $14,6 \%$ \\
\hline
\end{tabular}

\section{Gráfico 1}

Percentagem de sobras (\%) por unidade e por componente de refeição - comparação com valor de referência

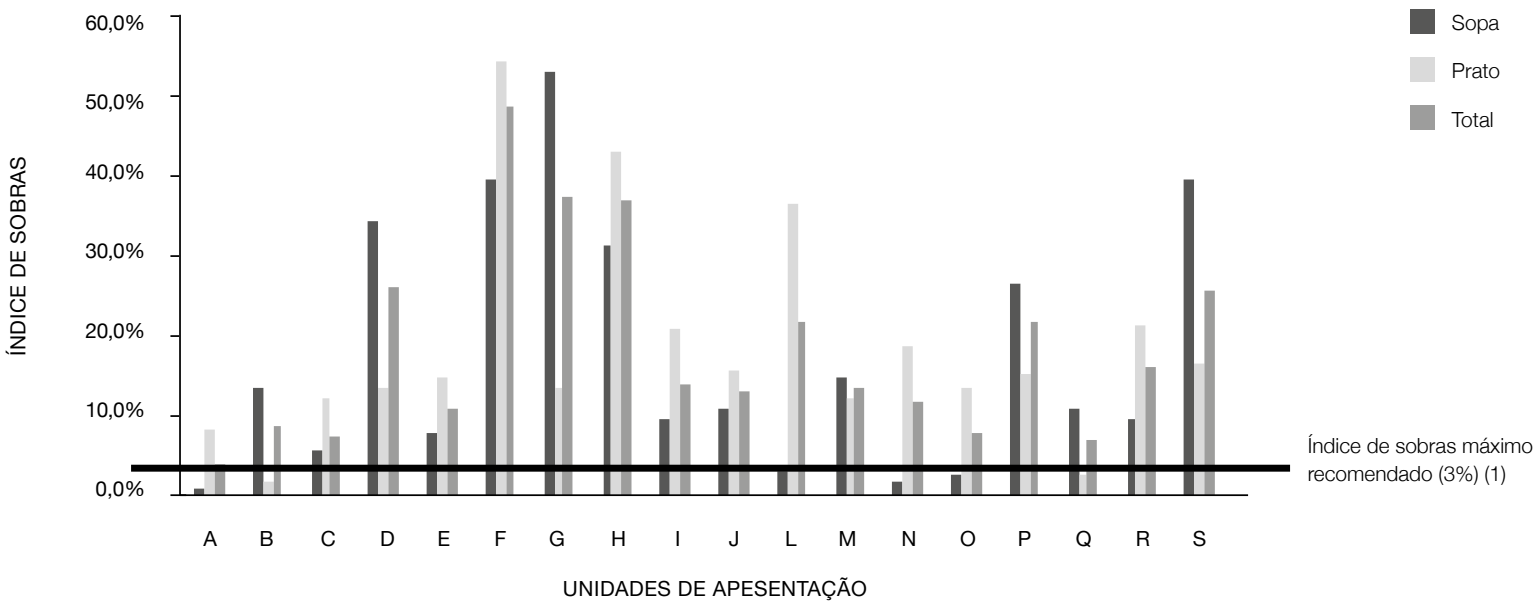


comparando o valor obtido com a literatura atual, o valor médio de sobras de 14,6\% é inferior a outros descritos na literatura que variam entre $17,8 \%$ e $28,7 \%(19,25-27)$. Por outro lado, existem estudos que apresentam valores inferiores a $14,6 \%$, mas ainda assim superiores ao limite descrito como aceitável, valores estes entre 6,87\% e 12,81\% (15, 17, 21-23, 28-30).

Elevados valores de sobras têm consequências económicas uma vez que as despesas mais relevantes são as que envolvem a matéria-prima (15), assim como todos os gastos associados à preparação dos alimentos, tais como água, luz e gás. Torna-se assim fulcral a redução do desperdício alimentar uma vez que esta redução poderá tornar os programas de alimentação escolar mais eficientes, através da redução dos custos inerentes (24).

O presente trabalho ao identificar as etapas de preparação com valores superiores de perdas, possibilita aos gestores das UAN estudar as causas e implementar estratégias com vista à sua minimização, bem como, trabalhar em conjunto com as escolas e autarquia na minimização de sobras.

Uma das limitações do presente trabalho foi a não contabilização das perdas decorrentes das batatas e, em alguns casos das cenouras, uma vez que o descasque destes alimentos foi realizado com recurso a uma máquina de descascar batatas, o que impossibilitou o acesso às cascas retiradas. A identificação do número de alunos faltosos com refeição marcada não foi recolhida, impossibilitando aferir o volume de sobras que resulta destas ausências.

\section{CONCLUSÕES}

O presente estudo evidenciou um valor de perdas de $14,2 \%$, o que demonstra uma oportunidade de melhoria no que respeita às técnicas de preparação aplicadas. O processo de descasque e a preparação da abóbora revelaram-se como a etapa e o alimento, respetivamente, que geraram perdas superiores ao longo do processo de produção de refeições. Relativamente às sobras, o valor médio encontrado (14,6\%) está acima dos limites recomendados pela literatura. A diminuição do desperdício alimentar é fundamental, sendo de enorme importância alertar as entidades competentes para esta problemática, como os Gestores das UAN, as Autarquias, as Direções e Agrupamentos de escolas, entre outros, com vista assim à melhoria do serviço prestado em cada UAN.

\section{AGRADECIMENTOS}

Este trabalho é financiado Fundos Nacionais através da FCT Fundação para a Ciência e a Tecnologia, no âmbito dos projetos UIDB/04033/2020, UIDB/50016/2020 e UIDB/05748/2020.

\section{REFERÊNCIAS BIBLIOGRÁFICAS}

1. Vaz C. Restaurantes - Controlando custos e aumentando lucros. Brasília: LGE. 2006.

2. Portugal Gd. Prevenir Desperdício Alimentar - Um compromisso de Todos!

2014. [Disponível em: http://www.iniav.pt/fotos/editor2/guia_prevenir_desperdicio_ alimentar.pdf].

3. Baptista P, Campos I, Plres I, Vaz S. Do Campo ao Garfo: Desperdício Alimentar em Portugal. CESTRAS. 2012.

4. Bagherzadeh M, Inamura M, Jeong H. Food Waste Along the Food Chain. OECD Food, Agriculture and Fisheries Papers. 2014;71.

5. FAO. Global Initiative on Food Loss and Waste Reduction. 2015.

6. Comissão E. Preparatory study on food waste across EU 272010.

7. Organização das Nações Unidas. Objetivos de Desenvolvimento Sustentável. 2015 [Available from: https://www.ods.pt/].

8. Gustavsson J, Cederberg C, Otterdijk R, Meybeck A. Global Food Losses and Food Waste: Extent, Causes and Prevention. Rome: Food and Agriculture Organization of the United Nations. 2011.

9. FAO. Food wastage footprint. Impacts on natural resources: Summary Report. 2013.

10. Ta'afaki J. Insights in Public Health: Food Waste in Hawai'i: A Global Problem Manifested Locally. Hawaii J Med Public Health. 2015;74(9):315-8.

11. Guthrie J, Buzby J. 2002. FoodReview - Economic Research Service Several strategies may lower plate waste in schoool feeding programs;25:36-42.

12. Lin AY, Huang ST, Wahlqvist ML. Waste management to improve food safety and security for health advancement. Asia Pacific journal of clinical nutrition. 2009;18(4):538-45. 13. Nonino-Borges CB, Rabito El, Silva Kd, Ferraz CA, Chiarello PG, Santos JSd, et al. Desperdício de alimentos intra-hospitalar. Revista de Nutrição. 2006;19:349-56.

14. Gomes GS. Avaliação do índice de resto-ingestão e sobras em uma unidade produtora de refeição comercial em Ipatinga - Minas Gerais. Nutrir Gerais. 2012;6(10):857-68

15. Augustini V, Kishimoto P, Tescaro T, Almeida F. Avaliação do índice de restoingestão e sobras em Unidade de Alimentação e Nutrição (UAN) de uma empresa metalúrgica na cidade de Piracicaba - São Paulo. Revista Simbio-Logias. 2008;1(1):99-110.

16. Akutsu RC, Botelho RA, Camargo EB, Sávio KEO, Araujo WC. A ficha técnica de preparação como instrumento de qualidade na produção de refeições. Rev. Nutr. 2005;18(2):277-9.

17. Lopes ACC. Avaliação do desperdício alimentar num Restaurante Universitário no Brasil: Tese de Licenciatura. Universidade Atlântica; 2011.

18. Rocha A, Santos MC, Afonso C, Franchini B, Morais C, Margarida Liz Martins Sistema de Planeamento e Avaliação de Refeições Escolares (SPARE) - Elaboração, verificação e monitorização na ótica do utilizador. FCNAUP [Internet]. 2014. [Disponível em: http://www.plataformacontraaobesidade.dgs.pt:8080/SPARE2/].

19. Silva M, Liz Martins M. Avaliação do desperdício alimentar ao longo do processo de produção de refeições e na fase de consumo num jardim-de-infância de uma IPSS. Acta Portuguesa de Nutrição. 2017; 9: 67.

20. Silvennoinen K, Heikkila L, Katajajuuri JM, Reinikainen A. Food waste volume and origin: Case studies in the Finnish food service sector. Waste Manag. 2015;46:140-5. 21. Muller PC. Avaliação do desperdício de alimentos na distribuição do almoço servido para os funcionários de um hospital público de Porto Alegre - RS: Tese de Bacharelato. Porto Alegre: Universidade Federal de Rio Grande do Sul; 2008.

22. Moura PN, Honaiser A, Bolognini MCM. Avaliação do índice de resto ingestão e sobras em Unidade de Alimentação e Nutrição (UAN) do Colégio Agrícola de Guarapuava (PR). Revista Salus-Guarapuava. 2009;3(1).

23. Rabelo NML, Alves TCU. Avaliação do percentual de resto-ingestão e sobra alimentar em uma unidade de alimentação e nutrição institucional. Revista Brasileira de Tecnologia Agroindustrial. 2016;10(1):2039-52.

24. Liz Martins M, Rodrigues SSP, Cunha LM, Rocha A. Factors influencing food waste during lunch of fourth-grade school children. Waste Manag. 2020;113:439-46. 25. Matos GMS, Vasconcelos Ts, Boudou F, Bernardino L. Avaliação do índice de resto-ingesta e sobras em uma Unidade de Alimentação e Nutrição (UAN) em uma rede hoteleira de Aracaju / SE. 2015. [Disponível em: https://portal.estacio.br/docs/ revista-horus/2015/HORUS_2015_OK_MATOS_E_VASCONCELOS.pdf].

26. Araújo L, Rocha A. Avaliação e controlo do desperdício alimentar em refeitórios escolares do Município de Barcelos. Acta Portuguesa de Nutrição. 2017:6-9.

27. Carvalho J, Lima J, Rocha A. Food waste and consumer satisfaction with the food service of Hotel and Tourism School of Coimbra, Portugal. Demetra. 2015;10(2):405-18. 28. Remini K. Avaliação quantitativa do desperdício alimentar na Santa Casa da Misericórida de Leiria: Tese de Mestrado - Faculdade de Medicina Veterinária da Universidade de Lisboa; 2018.

29. Ferreira M, Martins ML, Rocha A. Food waste as an index of foodservice quality. British Food Journal. 2013;115(11):1628-37.

30. Issa RC, Moraes LF, Francisco RR, dos Santos LC, dos Anjos AF, Pereira SC. [School meals: planning, production, distribution, and adequacy]. Rev Panam Salud Publica. 2014;35(2):96-103. 